\title{
COMMENTARY
}

\section{Statins STAT for (over)ventilated patients?}

\author{
Wolfgang M Kuebler, ${ }^{1,2 *}$ \\ See related research by Müller et al., http://ccforum.com/content/14/4/R143
}

\begin{abstract}
A decade after the introduction of lung-protective ventilation strategies with low tidal volumes, the adverse effects of mechanical ventilation remain a scientific and clinical challenge. This situation has fueled the search for adjuvant pharmacological strategies to advance the benefit of protective ventilation in an additive or synergistic manner. In a recent issue of Critical Care, Müller and coworkers demonstrate convincingly that the initiation of high-dose simvastatin treatment prior to the onset of mechanical ventilation can attenuate adverse effects in overventilated mice. The present commentary discusses the need for adjuvant therapy in mechanical ventilation, the scientific rational for statin therapy in this context, and potential limitations for its implementation into clinical practice.
\end{abstract}

In a recent issue of Critical Care, Müller and coworkers [1] report the results of an elegant experimental study in which they evaluated the therapeutic potential of highdose simvastatin $(20 \mathrm{mg} / \mathrm{kg})$ in overventilated mice. A decade after the landmark studies by Amato and the Acute Respiratory Distress Syndrome Network highlighted the clinical benefit of lung-protective ventilation strategies, the challenge posed by ventilator-induced lung injury (VILI) remains far from resolved. First, the proportion of patients who actually receive lung-protective ventilation with tidal volumes below $8 \mathrm{ml} / \mathrm{kg}$ remains modest [2,3]. Second, regional atelectasis, edema or compliance heterogeneities in injured lungs promote overdistension of less affected lung areas even with lung-protective ventilation due to redistribution of tidal volumes $[4,5]$. Third, the term 'lung-protective ventilation' is a relative one. Experimental data from murine models

\footnotetext{
${ }^{*}$ Correspondence: kueblerw@smh.ca

'The Keenan Research Centre at the Li Ka Shing Knowledge Institute of St Michael's Hospital

2Department of Surgery, University of Toronto, M5B 1W8 Toronto, ON, Canada
}

suggest that just several hours of lung-protective ventilation in previously healthy lungs suffice to cause pro-inflammatory responses, loss of barrier function and histological signs of lung injury [6].

As a consequence, adjuvant pharmacological options that support lung-protective ventilation strategies are in dire need. Drugs previously approved for other indications are particularly attractive in this context, since they can be rapidly implemented into clinical practice. Statins are HMG-CoA reductase inhibitors that were initially introduced into clinics for their ability to reduce low density lipoprotein and cholesterol levels. Yet, it soon became evident that they exhibit considerable pleiotropy, that is, biological effects that are independent of their lipid lowering properties. Cardiovascular pleiotropic effects of statins comprise improved endothelial function and bioavailability of nitric oxide (NO) as well as antiinflammatory, anti-oxidant and anti-coagulatory properties [7]. These pharmacological characteristics fulfill many aspects of the desired profile of an adjuvant therapy for VILI, in which the formation and release of inflammatory mediators [8] and reactive oxygen species [9] and the activation of platelets [10] are considered key pathogenic factors. Pleiotropic effects on endothelial cells resulting in improved bioavailability of NO may be of additive benefit in light of the recent identification of TRPV4 (transient receptor potential vanilloid 4) as a stretchsensitive $\mathrm{Ca}^{2+}$ entry channel in the pulmonary endothelium that plays an indispensable role in overventilation-induced hyperpermeability both in isolated lungs [11] and in vivo [12]. Importantly, stretch-induced endothelial $\mathrm{Ca}^{2+}$ influx via TRPV4 and subsequent lung vascular barrier failure are negatively regulated by endothelial-derived NO [13]. Improved NO bioavailability may therefore protect barrier function by inhibiting the critical activation of TRPV4 channels in overventilated lungs.

Müller and colleagues [1] provide convincing evidence in support of a beneficial effect of statin treatment in VILI. Mice overventilated for 6 hours with tidal volumes of $12 \mathrm{ml} / \mathrm{kg}$ showed characteristic signs of VILI, including recruitment of neutrophils and monocytes, release of inflammatory cytokines, ultrastructural evidence of endothelial cell injury, vascular hyperpermeability, and 
impaired pulmonary gas exchange. Pretreatment of mice with intraperitoneal injections of $20 \mathrm{mg} / \mathrm{kg}$ simvastatin 24 hours and 1 hour prior to the onset of mechanical ventilation attenuated these detrimental effects. As lipid plasma levels did not differ between groups, this therapeutic benefit was clearly attributable to the pleiotropic properties of statins. While these data provide principal proof-of-concept that statins may present a promising adjuvant strategy in patients undergoing mechanical ventilation, their translation into clinical practice requires careful consideration. First, the administered simvastatin dose of $20 \mathrm{mg} / \mathrm{kg} /$ day exceeds the currently highest approved clinical dose of $80 \mathrm{mg} /$ day by far, thus raising the likelihood of serious statin-associated adverse effects, such as myopathy or interstitial lung disease, in patients. Second, while simvastatin treatment effectively attenuated inflammatory responses in the lungs, it did not reduce the systemic inflammatory response to overventilation, as indicated by the unabated elevation of plasma cytokine levels and leukocytosis. As secondary injury to extra-pulmonary organs is considered to contribute critically to ventilation-dependent morbidity and mortality [14], it remains to be shown whether the demonstrated lung-protective effect of simvastatin can translate into an improved long-term clinical outcome. Last but not least, just as for the proven effectiveness of statins in the primary prevention of coronary heart disease [15], the implementation of prophylactic statin treatment prior to or with the onset of any mechanical ventilation may simply not be affordable or cost-effective on a larger scale.

Regardless of these concerns currently opposing the rapid clinical implementation of statin prevention for mechanical ventilation, the auspicious concept of adjuvant pharmacological therapy in support of lungprotective ventilation deserves in-depth evaluation and scientific pursuit with the aim to either overcome these limitations or to identify superior alternative adjuvant pharmaceuticals.

\section{Abbreviations}

NO, nitric oxide; TRPV4, transient receptor potential vanilloid 4; VILI, ventilatorinduced lung injury.

\section{Competing interests}

The author declares that he has no competing interests.
Published: 20 December 2010

\section{References}

1. Müller HC, Hellwig K, Rosseau S, Tschernig T, Schmiedl A, Gutbier B, Schmeck B, Hippenstiel S, Peters H, Morawietz L, Suttorp N, Witzenrath M: Simvastatin attenuates ventilator-induced lung injury in mice. Crit Care 2010, 14:R143.

2. Brunkhorst FM, Engel C, Ragaller M, Welte T, Rossaint R, Gerlach H, Mayer K, John S, Stuber F, Weiler N, Oppert M, Moerer O, Bogatsch H, Reinhart K, Loeffler M, Hartog C: Practice and perception - a nationwide survey of therapy habits in sepsis. Crit Care Med 2008, 36:2719-2725.

3. Weinert CR, Gross CR, Marinelli WA: Impact of randomized trial results on acute lung injury ventilator therapy in teaching hospitals. Am J Respir Crit Care Med 2003, 167:1304-1309.

4. Gattinoni L, Pesenti A: The concept of "baby lung". Intensive Care Med 2005, 31:776-784.

5. Mertens M, Tabuchi A, Meissner S, Krueger A, Schirrmann K, Kertzscher U, Pries AR, Slutsky AS, Koch E, Kuebler WM: Alveolar dynamics in acute lung injury: heterogeneous distension rather than cyclic opening and collapse. Crit Care Med 2009, 37:2604-2611.

6. Akram A, Han B, Masoom H, Peng C, Lam E, Litvack L, Bai X, Shan Y, Hai T, Batt J, Slutsky AS, Zhang H, Kuebler WM, Haitsma JJ, Liu M, dos Santos CC: Activating transcription factor 3 confers protection against ventilatorinduced lung injury. Am J Respir Crit Care Med 2010, 182:489-500.

7. Davignon J: Beneficial cardiovascular pleiotropic effects of statins. Circulation 2004, 109:|||39-|||43.

8. Tremblay L, Valenza F, Ribeiro SP, Li J, Slutsky AS: Injurious ventilatory strategies increase cytokines and c-fos m-RNA expression in an isolated rat lung model. J Clin Invest 1997, 99:944-952.

9. Papaiahgari S, Yerrapureddy A, Reddy SR, Reddy NM, Dodd O, Crow MT, Grigoryev DN, Barnes K, Tuder RM, Yamamoto M, Kensler TW, Biswal S, Mitzner W, Hassoun PM, Reddy SP: Genetic and pharmacologic evidence links oxidative stress to ventilator-induced lung injury in mice. Am J Respir Crit Care Med 2007, 176:1222-1235.

10. Yiming MT, Lederer DJ, Sun L, Huertas A, Issekutz AC, Bhattacharya S: Platelets enhance endothelial adhesiveness in high tidal volume ventilation. Am J Respir Cell Mol Biol 2008, 39:569-575.

11. Hamanaka K, Jian MY, Weber DS, Alvarez DF, Townsley MI, Al-Mehdi AB, King JA, Liedtke W, Parker JC: TRPV4 initiates the acute calcium-dependent permeability increase during ventilator-induced lung injury in isolated mouse lungs. Am J Physiol Lung Cell Mol Physiol 2007, 293:L923-L932.

12. Mertens M, Yin W, Liedtke W, Uhlig S, Kuebler WM: TRPV4-deficiency protects overventilated mice from lung edema but not inflammation [abstract]. Am J Respir Crit Care Med 2010, 181:A1676.

13. Yin J, Hoffmann J, Kaestle SM, Neye N, Wang L, Baeurle J, Liedtke W, Wu S, Kuppe H, Pries AR, Kuebler WM: Negative-feedback loop attenuates hydrostatic lung edema via a cGMP-dependent regulation of transient receptor potential vanilloid 4. Circ Res 2008, 102:966-974.

14. Kuebler WM: From a distance: ventilation-dependent extra-pulmonary injury. Trans/ Res 2010, 155:217-219.

15. Downs JR, Clearfield M, Weis S, Whitney E, Shapiro DR, Beere PA, Langendorfer A, Stein EA, Kruyer W, Gotto AM Jr: Primary prevention of acute coronary events with lovastatin in men and women with average cholesterol levels: results of AFCAPS/TexCAPS Air Force/Texas Coronary Atherosclerosis Prevention Study. JAMA 1998, 279:1615-1622.

doi:10.1186/cc9318

Cite this article as: Kuebler WM: Statins STAT for (over)ventilated patients? Critical Care 2010, 14:1014. 